\title{
Curcuma longa and Boswellia Serrata for improving functional status in osteoarthritis patients: From bench to bedside evidences
}

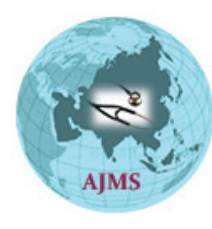

\author{
Rizaldy Taslim Pinzon', Vincent Ongko Wijaya ${ }^{2}$ \\ ${ }^{1}$ Lecturer, Department of Neurology, Faculty of Medicine, Duta Wacana Christian University, Yogyakarta, Indonesia, \\ ${ }^{2}$ Research Assistant, Department of Neurology, Faculty of Medicine, Duta Wacana Christian University, Yogyakarta, \\ Indonesia
}

A B S TR A C T

Background: The management of osteoarthritis (OA) represents a real challenge. Curcumin is a highly pleiotropic molecule with an excellent safety profile.Some previous studies showed the extract of Curcuma longa and Boswellia Serrata(CB extract) is a promising potential as therapeutic interventions against OA. Aims and Objective: This study aimed to measure the effectiveness and safety of $C B$ extract for improving functional status in patients with OA. Materials and Methods: $A$ randomized controlled trial (RCT) in OA patients. The treatment used in this trial were CB extract $(350 \mathrm{mg}$ of Curcuma longa and $150 \mathrm{mg}$ Boswellia Serrata) and NSAID (400 mg ibuprofen or $50 \mathrm{mg}$ diclofenac sodium). Subjects were randomized to 3 different group (Group 1: CB extract and NSAID; group 2: CB extract; group 3: NSAID). Each subject would be followed up 3 times: baseline (visit I), 2 weeks after baseline (visit II), and 4 weeks after baseline (visit III). The measurement of functional status with WOMAC (Western Ontario and McMaster Universities Osteoarthitis Index). Results: There were 105 osteoarthritis patients. Seven subjects were lost to follow up and three subjects were excluded from the study due to medication side effect. Ninety-five subjects (group 1: 36; group 2: 29, group 3: 30) remained for complete analysis. Delta $(\Delta)$ WOMAC score defined as the result of subtraction between WOMAC score at visit I and WOMAC score at visit III. Group 1 showed the greatest reduction of WOMAC score after 4 weeks of treatment $(\triangle W O M A C=12.08 \pm 18.6)$. Group 3 has the least WOMAC score reduction $(\triangle W O M A C=6.9 \pm 16)$. There was no statistically different of $\triangle$ WOMAC score between groups ( $p=0.367)$. There were no statistically different of the prevalence of $A E$ between groups at the visit II (p: 0.119) and at the visit III ( $p$ : 0.767). Conclusion: CB extract is effective and safe for improving functional status in OA patients.

Key words: Curcuma longa; Boswellia serrate; Osteoarthritis; WOMAC DOI: 10.3126/ajms.v10i5.24918 E-ISSN: 2091-0576 P-ISSN: 2467-9100

\section{INTRODUCTION}

The management of osteoarthritis $(\mathrm{OA})$ is a challenge. As a multifactorial disease evolving over decades, $\mathrm{OA}$ is one of the most disabling rheumatic diseases. In addition, no cure has been discovered to date. There is growing interest in the medical management of OA. However, this area requires new therapeutic strategies and approaches to deal with $\mathrm{OA}$ in a rapidly growing elderly population. ${ }^{1}$
Many pre-clinical evidences support the use of curcumin in OA. Most of the biological effects observed and published for curcumin in chondrocytes and OA between 2002 and 2009 were reported in previous narrative review. ${ }^{2,3}$

Over the last few decades many scientific and clinical studies have focused on the potential of curcumin for treating various pathological conditions. ${ }^{4}$ Curcumin was investigated mainly for its anti- inflammatory and

Address for Correspondence:

Dr. Rizaldy Taslim Pinzon, Department of Neurology, Faculty of Medicine, Duta Wacana Christian University, Wahidin Sudirohusodost. 5-25, Yogyakarta, Indonesia. Tel. No: +62 81294638229. E-mail: drpinzon17@gmail.com (c) Copyright AJMS 
anti-oxidant potency. Recently, these therapeutic effects have been reviewed in depth by Gupta et al.,5,

Only a few clinical studies have been published with curcumin. Curcumin was tested in patients suffering rheumatoid arthritis. In addition to be safe and not related to any adverse events, curcumin $(500 \mathrm{mg})$ was the most effective to improve disease activity score (DAS) and American College of Rheumatology (ACR) score. Curcumin was administered alone or in combination with diclofenac sodium $(50 \mathrm{mg}) .^{7}$ Despite the paucity of published clinical data on curcumin and the overall poor quality of the trials, there is scope for promising future studies on curcumin in OA. However, since the in vitro effect was so well- documented and proven, the clinical efficacy needs to be further studied in OA patients. This study aimed to measure the effectiveness of Curcuma longa and Boswellia Serrata (CB extract) for improving functional status in $\mathrm{OA}$ patients.

\section{MATERIALS AND METHODS}

\section{Study design}

This was a randomized controlled trial (RCT) in OA patients. Computerized generated block randomization with openepi software is used in this study. The treatment used in this trial were CB extract (350 mg of Curcuma longa and $150 \mathrm{mg}$ Boswellia Serrata) and NSAID (400 mg ibuprofen or $50 \mathrm{mg}$ diclofenac sodium). Each subject would be followed up 3 times: baseline (visit I), 2 weeks after baseline (visit II), and 4 weeks after baseline (visit III). The measurement was using WOMAC (Western Ontario and McMaster Universities Osteoarthitis Index).

\section{Subjects}

Subject Inclusion criteria for this study are: male or female patients, age $>18$ years old, and has knee osteoarthritis with Kellgren-Lawrence grade II or III. Subject with a known hypersensitivity to $\mathrm{CB}$ extract, ibuprofen, diclofenac sodium, participation in other clinical trial in the last 1 month before this study, pregnant or has a pregnancy program, incompetent to give a consent and answer the questionnaire, or receiving other pain treatment in the last 24 hours before this study was excluded in this study. The minimum sample requirement was 25 subjects in each group. Total of 100 subjects were enrolled for achieving normal distribution.Subjects were randomized to 3 different group (Group 1: CB extract and NSAID; group 2: $\mathrm{CB}$ extract; group 3: NSAID). Each medication was taken two times per day for 4 weeks.

\section{Variable}

Demographic profile including sex, age, occupation, marital status, education background, comorbidity, and the degree of OA. The degree of knee OA was measured using Kellgren-Lawrence (KL) grading scale. WOMAC (Western Ontario and McMaster Universities Osteoarthitis Index) commonly used as a standardized questionnaires to evaluate the functional status of patients with osteoarthritis. It consists of 3 categories of questions, 5 questions for pain, 2 questions for stiffness, and 17 questions for physical functioning of the joints. Each question is scored on a scale of 0 to $4(0=$ none, $1=$ mild, $2=$ moderate, $3=$ severe, $4=$ extreme), thus score range for pain, stiffness, and physical functioning are $0-20,0-8$, and $0-68$ respectively. The total score for all questions is 96 . The higher score indicates the worse OA symptom. Any adverse event (AE) in this trial would be reported and monitored strictly. This study was approved by Duta Wacana Christian University School of Medicine Ethical Research Committee, Yogyakarta, Indonesia. The number of ethical clearance is $867 / \mathrm{C} .16 / \mathrm{FK} / 2018$.

\section{Analysis}

The analysis of this study is intention to treat based. After normality test with Kolmogorov-Smirnov test, numeric variables analyzed using $\mathrm{t}$-test or wilcoxon signed rank test. Based on the result of homogenity test, ANOVA or Kruskal Wallis test used to identify the mean differences between three groups. The significant level was set at $\mathrm{p}<0.05$.

\section{RESULTS}

There were 105 subjects at the beginning of the study. Most of the study subjects were female (80\%) with mean aged 63 years. About $57.1 \%$ of subjects have osteoarthritis with KL grade II. Seven subjects were lost to follow up and three subjects were excluded from the study due to medication side effect. Ninety-five subjects (36 subjects from group 1, 29 subjects from group 2, 30 subjects from group 3) remained for complete analysis (Table 1).

\begin{tabular}{lc}
\hline \multicolumn{2}{l}{ Table 1: The subjects' characteristics } \\
\hline Characteristics & $\mathbf{n ~ ( \% )}$ \\
\hline Age (mean) & $63.24 \pm 8.77$ \\
Gender & \\
Male & $21(20 \%)$ \\
Female & $84(80 \%)$ \\
Marital status & \\
Married & $78(74.3 \%)$ \\
Not married & $27(25.7 \%)$ \\
Occupation & \\
Employe & $70(66.7 \%)$ \\
Not employe & $35(33.3 \%)$ \\
KL Grade & \\
Grade II & $60(57.1 \%)$ \\
Grade III & $45(42.9 \%)$ \\
Comorbidity & \\
Yes & $79(75.2 \%)$ \\
No & $26(24.8 \%)$ \\
\hline
\end{tabular}

Asian Journal of Medical Sciences | Sep-Oct 2019 | Vol 10 | Issue 5 


\begin{tabular}{|c|c|c|c|c|c|c|c|}
\hline \multirow[t]{2}{*}{ Group } & \multicolumn{3}{|c|}{ WOMAC I (n=105) } & \multicolumn{3}{|c|}{ WOMAC III (n=95) } & \multirow[t]{2}{*}{$p$} \\
\hline & $\begin{array}{l}\text { Min. } \\
\text { Score }\end{array}$ & $\begin{array}{l}\text { Max. } \\
\text { Score }\end{array}$ & $\begin{array}{l}\text { Mean. } \\
\text { Score }\end{array}$ & $\begin{array}{l}\text { Min. } \\
\text { Score }\end{array}$ & $\begin{array}{l}\text { Max. } \\
\text { Score }\end{array}$ & $\begin{array}{l}\text { Mean. } \\
\text { Score }\end{array}$ & \\
\hline All subjects & 3 & 73 & $39.7 \pm 19$ & 0 & 84 & $27.9 \pm 21$ & $<0.001$ \\
\hline Group 1 & 5 & 73 & $41.4 \pm 19$ & 2 & 84 & $30.3 \pm 22$ & $<0.001$ \\
\hline Group 2 & 5 & 73 & $33.9 \pm 17$ & 0 & 79 & $26.4 \pm 20$ & $<0.001$ \\
\hline Group 3 & 3 & 69 & $34.3 \pm 20$ & 1 & 65 & $26.7 \pm 21$ & 0.016 \\
\hline
\end{tabular}

Table 2 showed the mean of WOMAC score at visit I and visit III from all subjects and from each group. The highest mean of WOMAC score was in group 1 and the least was in group 2. The reduction of WOMAC score from visit I to visit III is statistically significant in all groups.

Delta $(\Delta)$ WOMAC score defined as the result of subtraction between WOMAC score at visit I and WOMAC score at visit III. The highest mean of WOMAC score was in group 1 (Table 3 and Figure 1). However, group 1 showed the greatest reduction of WOMAC score after 4 weeks of treatment $(\triangle \mathrm{WOMAC}=12.08 \pm 18.6)$. Group 3 has the least WOMAC score reduction. There was no statistically different of $\triangle$ WOMAC score between groups (Table 3).

Group 3 was the most frequently group with reported AE, whereas group 2 has the least reported AE. Abdominal pain was the most common type of $\mathrm{AE}(\mathrm{n}=7)$. All of them were seen in group 3 . Three subjects need to discontinue the medication due to the $\mathrm{AE}$, two among them were subjects in group 3 and one among them was subject in group 2 . No fatal AE was reported in all groups and no subject needed an inpatient treatment due to the AE. After a further investigation, only one case (dizziness) of $\mathrm{AE}$ that related to the administration of $\mathrm{CB}$ extract and 5 cases (abdominal pain) related to the administration of NSAID. There were no statistically different of the prevalence of AE between groups at the visit II (p: 0.119) and at the visit III (p: 0.767).

\section{DISCUSSION}

\section{Pre clinical evidences}

The anti-inflammatory property of curcumin has been investigated and explained by studies showing how curcumin acts on inflammatory pathways. Curcumin $(50 \mu \mathrm{M})$ was shown to inhibit NF- $x \mathrm{~B}$ activation and translocation induced by IL-1 $\beta$ and the consequent expression of $\mathrm{NF}-x \mathrm{~B}$ induced pro-inflammatory genes, COX-2 and VEGF. ${ }^{8}$ Another study has described its effect on signaling and its inhibitory potency in chondrocytes in agarose constructs. ${ }^{9}$ Curcumin $(0.01-100 \mathrm{ng} / \mathrm{ml})$ was used for its potency to inhibit activator protein (AP)-1 and reverse the IL- $1 \beta$ stimulated production of nitric oxide $(\mathrm{NO})$ and prostaglandin $\mathrm{E}_{2}\left(\mathrm{PGE}_{2}\right)$.

\begin{tabular}{lcc} 
Table 3: The mean of $\triangle$ WOMAC score & \\
\hline Medication & Mean $\Delta$ WOMAC & $\mathbf{p}$ \\
\hline Group 1 (n: 36) & $12.08 \pm 19$ & 0.367 \\
Group 2 (n: 29) & $7.2 \pm 14$ & \\
Group 3 (n: 30) & $6.9 \pm 16$ & \\
\hline
\end{tabular}

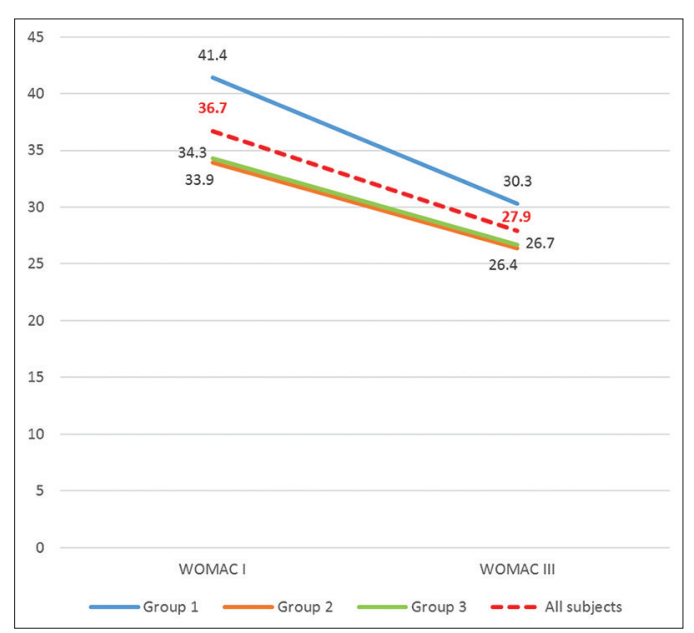

Figure 1: The comparison of WOMAC score mean

Curucmin was able to produce an anti-inflammatory effect by inhibiting the pro-inflammatory mediators, i.e. PGE2, NO, IL-6 and IL-8. However, in contrast to NSAIDs, curcumin inhibited COX-2, but not COX-1 gene expression..$^{10}$ The antiinflammatory potency of curcumin was also demonstrated in another connective tissue cell type. Curcumin $(5 \mu \mathrm{M})$ was shown to modulate inflammation in human tenocytes by the inhibition of COX-2 through its effect on NF- $x \mathrm{~B}$ and on other related and equally important cell signaling pathway - the phosphatidylinositol-3 kinase/Akt pathway. ${ }^{11}$

\section{Clinical evidences}

Our study show promising result. The result similar with other clinical studies. The clinical efficacy of curcumin was tested in OA patients receiving a patented complex with phosphatidylcholine that improved curcumin bioavailability. ${ }^{12}$ This study investigated efficacy and safety of the compound on a longer term ( 8 months). The evaluation included the measurement of several markers of inflammation (IL-1 $\beta$, IL-6, sCD40L, sVCAM-1, ESR). One hundred OA patients were included in this study. The add on of curcumin to standard therapy, significantly 
reduced pain and stiffness and improved joint function. All WOMAC scores were improved by the treatment with add on curcumin therapy including social and emotional function. Finally, the markers of inflammation were significantly decreased in the treatment group between enrollment and after 8 months of treatment.

A recent study showed that CL extract, BS extract, or its combination was beneficial in OA patients. About 201 subjects were investigated in a three-arm, parallelgroup, randomized, double-blinded, placebo-controlled trial to identify the effects of $333 \mathrm{mg}$ curcuminoids and a combination of $350 \mathrm{mg}$ curcuminoids and $150 \mathrm{mg}$ boswellic acid. The administration of combination of curcumin and boswellic acid had a superior effect size (physical performance tests and the WOMAC joint pain index) than curcuminoid alone. ${ }^{13}$

\section{Further research}

The promising in vitro results and the interesting clinical observations gathered here for curcumin should refocus efforts to develop therapies based on new formulations of curcumin. Well-designed clinical studies are needed to determine and document the efficacy of curcumin and combination products with curcumin in $\mathrm{OA}$ patients.

Hence, curcumin represents a new paradigm since it is not yet a recommended intervention in OA but should be considered based on its safety and efficacy. In addition, taken altogether, these data highlight the needs in OA research for the near future as good quality and well-designed trials.

\section{CONCLUSION}

$\mathrm{CB}$ extract is effective and safe for improving functional status in $\mathrm{OA}$ patients. Further clinical studies are warranted to determine the efficacy of curcumin and its combination products for OA patients.

\section{Data availability}

The data used to support the findings of this study are available from the corresponding author upon request.

\section{Conflict of interest}

The authors declare that they do not have any conflicts of interest.

\section{REFERENCES}

1. Henrotin $Y$, Clutterbuck AL, Allaway D, Lodwig EM, Harris $P$, Mathy-Hartert M, et al.Biological actions of curcumin on articular chondrocytes. Osteoarthritis and cartilage/OARS, Osteoarthritis Res Soc2010; 18 (2):141-149.

2. Shen C-L, Smith BJ, Lo D-F, Chyu M-C, Dunn DM, Chen C-H, et al. Dietary polyphenols and mechanisms of osteoarthritis. J NutrBiochem2012; 23(11):1367-1377.

3. Henrotin Y, Lambert C, Couchourel D, Ripoll C and Chiotelli E. Nutraceuticals: do they represent a new era in the management of osteoarthritis? - a narrative review from the lessons taken with five products. Osteoarthritis and cartilage/OARS, Osteoarthritis Res Soc 2011; 19(1):1-21.

4. Goel A, Kunnumakkara $A B$ and Aggarwal BB. Curcumin as "Curecumin": from kitchen to clinic. BiochemPharmacol2008; 75(4):787-809.

5. Gupta SC, Patchva S and Aggarwal BB. Therapeutic Roles of Curcumin: Lessons Learned from Clinical Trials.AAPS J;2012.

6. Gupta SC, Patchva S, Koh W and Aggarwal BB. Discovery of curcumin, a component of golden spice, and its miraculous biological activities. ClinExpPharmacolPhysiol2012; 39(3):283-299.

7. Chandran B and Goel AA. Randomized, Pilot Study to Assess the Efficacy and Safety of Curcumin in Patients with Active Rheumatoid Arthritis. Phytother Res; PTR,2012; 26(11):1719-25.

8. Csaki C, Mobasheri A and Shakibaei M. Synergistic chondroprotective effects of curcumin and resveratrol in human articular chondrocytes: inhibition of IL-1beta-induced NFkappaB-mediated inflammation and apoptosis. Arthritis Res Ther2009; 11(6):R165.

9. Chowdhury TT, Salter DM, Bader DL and Lee DA. Signal transduction pathways involving p38 MAPK, JNK, NFkappaB and AP-1 influences the response of chondrocytes cultured in agarose constructs to IL-1beta and dynamic compression. Inflammation Res: J Eu Histamine Res Soc2008; 57(7):306-313.

10. Mathy M, Sanchez C, Priem F and Henrotin Y. Curcumin inhibits interleukin-6, -8, nitric oxide and prostaglandin E2 synthesis by bovine chondrocytes. OsteoarthrCartil/OARS, Osteoarthr Res Soc2007; 15(Suppl C):C115.

11. Buhrmann $\mathrm{C}$, Mobasheri $\mathrm{A}$, Matis $U$ and Shakibaei M. Curcumin mediated suppression of nuclear factor-kappaB promotes chondrogenic differentiation of mesenchymal stem cells in a high-density co-culture microenvironment. Arthritis Res Ther2010; 12(4):R127.

12. Belcaro G, Cesarone MR, Dugall M, Pellegrini L, Ledda A, Grossi MG, et al. Efficacy and safety of Meriva(R), a curcumin- phosphatidylcholine complex, during extended administration in osteoarthritis patients. Alternative Med Rev: J Clin Therapeutic 2010; 15(4):337-344.

13. Haroyan A, Mukuchyan V, Mkrtchyan N, Minasyan N, Gasparyan S, Sargsyan A, et al. Efficacy and safety of curcumin and its combination with boswellic acid in osteoarthritis: a comparative, randomized, double-blind, placebo-controlled study. BMC Complementary and Alternative Medicine2018; 18:7.

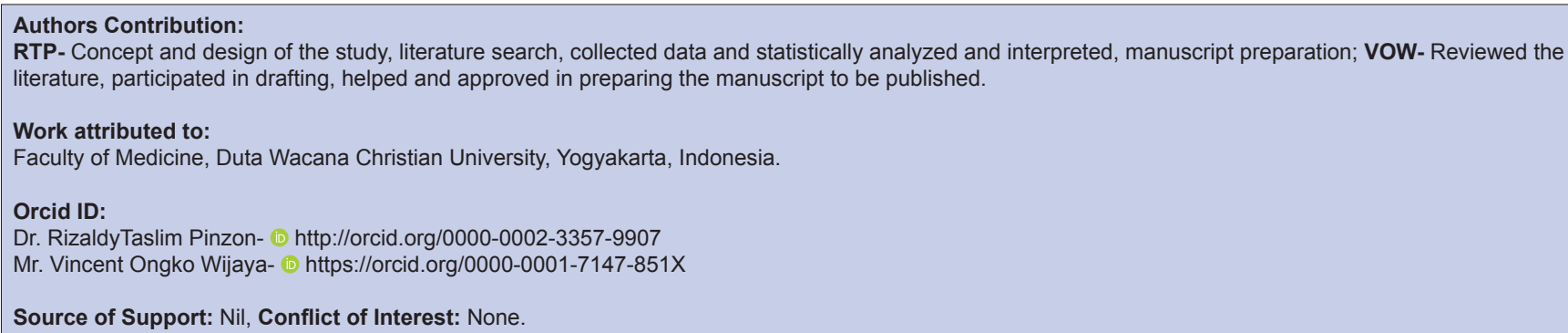




\section{APPENDIX}

\begin{tabular}{|c|c|c|c|c|c|c|}
\hline \multicolumn{5}{|l|}{ PATIENT NAME } & \multicolumn{2}{|l|}{$\overline{D O B}$} \\
\hline \multicolumn{6}{|c|}{$\begin{array}{l}\text { WESTERN ONTARIO AND } \\
\text { MCMASTER OSTEOARTHRITIS INDEX (WOMAC) } \\
\text { Please circle the appropriate rating for each item. }\end{array}$} & \\
\hline RATE YOUR PAIN WHEN... & NONE & SLGHT & MODERATE & SEVERE & EXTREME & \begin{tabular}{|c|} 
HOSPITAL USE \\
ONLY
\end{tabular} \\
\hline Walking & 0 & 1 & 2 & 3 & 4 & \multirow[b]{5}{*}{ TOTAL } \\
\hline Climbing stairs & 0 & 1 & 2 & 3 & 4 & \\
\hline Sleeping at night & 0 & 1 & 2 & 3 & 4 & \\
\hline Resting & 0 & 1 & 2 & 3 & 4 & \\
\hline Standing & 0 & 1 & 2 & 3 & 4 & \\
\hline RATE YOUR STIFFNESS IN THE... & NONE & suant & MODERATE & SEVERE & EXTREME & $\begin{array}{c}\begin{array}{c}\text { HOSPITAL USE } \\
\text { ONLY }\end{array} \\
\end{array}$ \\
\hline Morning & 0 & 1 & 2 & 3 & 4 & \multirow[b]{2}{*}{ TOTAL } \\
\hline Evening & 0 & 1 & 2 & 3 & 4 & \\
\hline RATE YOUR DIFFICULTY WHEN... & NONE & sught & MODERATE & SEVERE & EXTREME & \begin{tabular}{|c|} 
HOSPITAL USE \\
ONLY
\end{tabular} \\
\hline Descending stairs & 0 & 1 & 2 & 3 & 4 & \\
\hline Ascending stairs & 0 & 1 & 2 & 3 & 4 & \\
\hline Rising from sitting & 0 & 1 & 2 & 3 & 4 & \\
\hline Standing & 0 & 1 & 2 & 3 & 4 & \\
\hline Bending to floor & 0 & 1 & 2 & 3 & 4 & \\
\hline Walking on even floor & 0 & 1 & 2 & 3 & 4 & \\
\hline Getting in/out of car & 0 & 1 & 2 & 3 & 4 & \\
\hline Going shopping & 0 & 1 & 2 & 3 & 4 & \\
\hline Putting on socks & 0 & 1 & 2 & 3 & 4 & \\
\hline Rising from bed & 0 & 1 & 2 & 3 & 4 & \\
\hline Taking off socks & 0 & 1 & 2 & 3 & 4 & \\
\hline Lying in bed & 0 & 1 & 2 & 3 & 4 & \\
\hline Getting in/out of bath & 0 & 1 & 2 & 3 & 4 & \\
\hline Sitting & 0 & 1 & 2 & 3 & 4 & \\
\hline Getting on/off toilet & 0 & 1 & 2 & 3 & 4 & \\
\hline Doing light domestic duties (cooking, dusting) & 0 & 1 & 2 & 3 & 4 & \\
\hline Doing heavy domestic duties (moving furniture) & 0 & 1 & 2 & 3 & 4 & TOTAL \\
\hline \multicolumn{4}{|l|}{ PATIENT SIGNATUAE } & \multicolumn{2}{|l|}{ DATE } & \\
\hline \multicolumn{4}{|l|}{ REVIEWED BY PHYSICAL THERAPIST } & \multicolumn{2}{|l|}{ DATE } & \begin{tabular}{|l|} 
WOIMC \\
TOTNL \\
SCORE
\end{tabular} \\
\hline
\end{tabular}

Western Ontario and McMaster Universities Arthritis Index (WOMAC) questionnaire 